\title{
Predictors of Reading Disability in Latvian Language With a Regular Orthography
}

\author{
Madara Orlovska, Malgozata Rascevska, Agnese Jaunzeme \\ University of Latvia, Riga, Latvia
}

\begin{abstract}
The current study sought to determine the most predictive reading and writing skills of RD (reading disability) in Latvian orthography, controlling for the level of intelligence. The subjects of the study were 41 monolingual Latvian pupils from Grades 1 and 2 with RD and 41 control children matched by age, gender, and grade (in both groups mean age $=98$ months, $56 \%$ boys, $50 \%$ Grade 1 ). Reading and writing skills of subjects were assessed with Latvian Language Achievement Test (Raščevska, Paegle, \& Mencis, 2013), some DIBELS Next (Good et al., 2011; Latvian version: Raščevska et al., 2013a) and newly developed reading tasks. Full Scale IQ (intelligence quotient) was determined with WISC-IV ${ }^{\mathrm{LV}}$ (Wechsler Intelligence Test for Children) (Wechsler, 2003; Latvian Edition: Raščevska, Sebre, \& Ozola, 2013). According to the results of alogistic regression model, RD in Latvian orthography was significantly predicted by nonsense word fluency, oral reading fluency, and accuracy of rare word decoding, when the level of intelligence was controlled. The results of the study are discussed in the context of previous findings about predictors of RD in various orthographies, and the role of intelligence in the identification of specific predictors of $\mathrm{RD}$.
\end{abstract}

Keywords: reading disability, reading skills, writing skills, intelligence, regular orthography, Latvian language

\section{Introduction}

A number of studies have suggested that the type of orthography plays an important role in reading, thus, the predictors of RD might differ in English with irregular orthography and in other languages with more regular orthographies (Aro, 2006; Davies, Cuetos, \& Glez-Seijas, 2007; Landerl et al., 2013). Latvian language has an alphabetic and a regular orthography with rather clearly defined syllable system (Skadina, Rehm, \& Uszkoreit, 2012). So far, in Latvian language some studies have been conducted concerning the cognitive and reading predictors of reading ability in the general population, not differentiating the RD group from the normative sample (Briede, 2005; Sprugevica \& Høien, 2004). The purpose of this study was to find out the most important predictors of $\mathrm{RD}$, controlling for the level of intelligence.

RD according to ICD-10 (International Statistical Classification of Diseases and Related Health Problems) is defined as a disability of reading acquisition that cannot be directly attributed to age-appropriate ability level, primary vision deficit, or inadequate reading instruction (World Health Organization, 1992). RD manifests as

\footnotetext{
*Acknowledgements: This work was supported by the European Social Fund within the project "Support for Doctoral Studies at University of Latvia".

Madara Orlovska, Department of Psychology, University of Latvia.

Malgozata Rascevska, Department of Psychology, University of Latvia.

Agnese Jaunzeme, Department of Psychology, University of Latvia.
} 
difficulties in word recognition, spelling, and/or reading comprehension and is prevalent across all IQ levels. The definition from ICD-10 is very similar to the definition in DSM-5 (the Diagnostic and Statistical Manual of Mental Disorders) where RD is considered as an integrated part of learning disabilities (American Psychiatric Association, 2013). Identification of RD in Latvia, as in other European countries, should be based on approaches from ICD-10. For identification of RD, the level of intelligence must be above 70 standard scores to exclude the possibility of primary mental retardation. Studies have shown that IQ is not associated with reading and reading-related skills (e.g., word or text reading), but is related to more general cognitive skills, whereas RD is associated with reading skills and phonological ability (Kortteinen, Närhi, \& Ahonen, 2009; Siegel, 1988). Although IQ scores should not be influenced by RD, learning disability may be causally related to a lower IQ score, and there may be a decrease in the IQ test scores for children with RD, perhaps as a consequence of reading failure (Stanovich, 1986). In the present study, level of intelligence was controlled.

Manifestations of RD in English-speaking children include decreased word and text reading fluency, various difficulties in areas of phonological ability and phonological processing reflected by nonsense word fluency, and poor reading comprehension (Herrmann, Matyas, \& Pratt, 2006; Velluntino, Fletcher, Snowling, \& Scanlon, 2004). Very often RD is accompanied by difficulties in writing (DSM-5; American Psychiatric Association, 2013), and may cause reading motivation difficulties: a desire to avoid reading (Paris, Wasik, \& Turner, 1991; Wigfield \& Guthrie, 1997). Children who have high avoidance of reading are not willing to engage in reading activities, and they perform less well on reading related tasks than other children (Baker \& Wigfield, 1999).

Studies of RD in German with a regular orthography advocate that children with RD are able to read long, unfamiliar words as accurately as children without RD (Frith, Wimmer, \& Landerl, 1998), however, their text reading fluency is decreased and sometimes reading comprehension is troubled (Wimmer, Mayringer, \& Landerl, 1998). Reading in regular orthographies provides higher rates of accuracy (Aro, 2006), and, even for children with RD, the process of reading is comparatively easier than in irregular orthographies (Landerl, Wimmer, \& Frith, 1997), thus RD manifests in a different form than in irregular orthographies. Studies in Spanish language (with a regular orthography) have confirmed that phonological difficulties are universal, but in languages with a regular orthography more typical difficulties in the case of RD are with rare word decoding accuracy (Lopez \& Jimenez-Gonzalez, 1999). In a study examining predictors of RD in regular (Finnish, Hungarian), quite regular (German, Dutch) and irregular (French, English) orthographies, phonological ability and rapid naming were the most powerful predictors in all orthographies, and the more complex the orthography was, the more these indices predicted a disability (Landerl et al., 2013). However, studies in Swedish and Norwegian have indicated that phonological ability diminishes as a predictor of RD in a regular orthography after Grade 1 (Furnes \& Samuelsson, 2010). Studies within languages of varying regularity of orthographies have reported the length effect in reading: Longer words are read more slowly, sometimes also less accurately than shorter words; the length effect is larger for less-skilled developing readers (Davies, Cuetos, \& Glez-Seijas, 2007; Ziegler et al., 2003). In the present study, primary pupils might be considered as developing readers and children with $\mathrm{RD}$ as less skilled readers than children without RD.

In the general population of Latvian primary pupils, naming speed predicted reading comprehension, whereas phonological awareness predicted reading comprehension indirectly through decoding (Sprugevica \& Høien, 2004); word reading fluency was strongly related to phonological ability and reading comprehension 
(Briede, 2005). However, the results of the studies mentioned above should be interpreted carefully because they were obtained in the general population, and the reliability indicators are missing for the measures. To our knowledge, no studies have attempted to determine predictors of RD in Latvian language using valid and reliable assessment tests. In comparison to English, Latvian language words are on average longer and phonological processing might be more involved while reading (Skadina, Rehm, \& Uszkoreit, 2012). Certainly, Latvian language is specific, perhaps also brings small changes to the nature of RD.

In the general population of Latvian primary pupils, reading skills are predicted by phonological awareness, word reading, and reading comprehension, but, so far, there are no empirical studies about predictors of $\mathrm{RD}$ using reliable assessment tests of reading and writing skills. It might be presumed that RD for Latvian pupils, similarly to other languages with a regular orthography, is predicted by rare word reading fluency and accuracy, phonological ability and reading comprehension. Regardless of the orthography, RD also might be predicted by phonological processing, long word reading, writing achievement, and reading avoidance. To obtain more precise results, the level of intelligence was measured and included in the model. This study sought to answer: What are the most predictive reading and writing skills for Latvian primary pupils with RD, controlling for the level of intelligence?

\section{Method}

\section{Subjects}

Subjects included 41 children with RD (mean age $=98.37$ months, $S D=6.88 ; 56 \%$ boys; $50 \%$ Grade 1 ) and 41 control children (mean age $=97.93$ months, $S D=7.00,56 \%$ boys; 50\% Grade 1). Groups were matched by gender, grade, and age. All pupils were native Latvian speakers from Grades 1 and 2. Pupils came from seven comprehensive schools from the capital city of Latvia, Riga, and from four schools in other regions of Latvia. T-test for independent samples found no significant differences in mean ages in months between the two groups, $t=-0.29, p=0.77$. Selection of children for the study was primarily made by availability, including only subjects whose parents had given written permission for child's participation.

Due to the fact that there are very few RD diagnoses in Latvia among pupils in Grades 1 and 2, the following strategy was used to select the subjects. During a conversation with a class teacher, the potential pupils with persistent RD were nominated (teachers had observed these children for at least five months, from September to February). In the second semester (from February to May) of school years 2012 to 2013 and 2013 to 2014, nominated children were assessed with RAT (Reading Achievement Test) from LLAT (Latvian Language Achievement Tests), and the children whose composite score in RAT was lower than one $S D$ below the mean score for the general population were included in RD group. Due to the fact that in every class, very few children met the previously mentioned criterion, additionally the RD group included children, whose scaled score $(M=10 ; S D=3)$ in one of the RAT subtests was 7 or lower, considering this to be a significant decline in one of the important components of reading ability. The criterion of RD was based only on the decreased score in decoding, while Retell from RAT that measures reading comprehension was not included. To administer Retell, the child must reach a frontier of 50 words read correct per minute which is very rarely reached by children from RD group. Besides, in the early stage of reading acquisition-Grades 1 and 2 - decoding more accurately reflects the construct of reading ability. The assessment of intelligence was also done, and those in the RD group were children whose Full Scale IQ in WISC-IV ${ }^{\mathrm{LV}}$ was $\geq 70$ composite score. 


\section{Measures}

Reading and writing achievement. RAT from LLAT (Raščevska, Paegle, \& Mencis, 2013) was used for the reading achievement measure. RAT consists of WNR (Word Non-Word Reading) and TR (Text Reading) subtests. Only one of the TR indicators - reading fluency (Without Retell) was used for assessment. Each task was performed for one minute. Sum of WNR and TR formed a composite score of RA-I (Reading Achievement Index). Spearman-Brown reliability coefficient in a normative sample of Latvia for WNL is $r_{s b}=0.97$, for TR is $r_{s b}=0.87$, and for RA-I is $r_{s b}=0.97$ (Raščevska, Paegle, \& Mencis, 2013, p. 92).

A part of WAT (Writing Achievement Test) from LLAT: NN (Noun and Numeral Spelling) was used for the assessment of writing. Only two of three of NN tasks were used in this study-NP (Noun Spelling from a Picture) and ND (Noun Spelling from a Dictation). Spearman-Brown reliability coefficient in a normative sample of Latvia for NN is $r_{s b}=0.97$ (Raščevska, Paegle, \& Mencis, 2013, p. 92).

Early literacy skills. Four tasks of DIBELS (Dynamic Indicators of Early Basic Literacy Skills) (Good et al., 2011; adaptation and standardisation in Latvia: Raščevska et al., 2013a): LNF (Letter Naming Fluency), PSF (Phoneme Segmentation Fluency), NWF (Nonsense Word Fluency) (WWC (Whole Words Correct) only), and DORF (DIBELS Oral Reading Fluency) (Without Retell) were used for pupils from both grades. Each task was performed for one minute. Test-retest reliability during a 2-3 month interval for LNF is $r=0.69, p<0.01$, for PSF is $r=0.72, p<0.01$, for NWF is $r=0.84, p<0.01$, and for DORF is $r=0.90, p<0.01$ (Raščevska et al., 2013b, pp. 65-66).

Reading comprehension. Latvian RC (Reading Comprehension) (Orlovska \& Rascevska, 2014b) task consists of a 117-word narrative story with 16 sentences; the average number of words per sentence is 7.31 and average number of letters per word is 5.30. The vocabulary and content of the story were appropriate for primary pupils. First, a child has to read the whole story and later answer eight questions about the content of the story. The response is evaluated on a scale from 0 to 2 ( 0 -Wrong; 1 -Partly correct; 2 - Correct). Total score of RC is the sum of correct or partly correct responses. Cronbach's Alpha reliability coefficient for RC is $\alpha=0.70$.

Frequent and rare word reading. LFRWR (Latvian Frequent and Rare Word Reading) (Orlovska \& Rascevska, 2014a) measures the ability to read words that are frequently or rarely encountered in their experience. LFRWR consists of 48 three-syllable words: 24 frequent words and 24 rare words in the experience of Latvian junior primary pupils. On average, words are composed of six letters. In each row, there are three rare and three frequent words distributed in a defined algorithm. The eight rows form one rare and one frequent word item. A child has to read all words as accurately as possible. One point is received for each word that is read correctly only once and for the first time. Points are calculated in the framework of each row, and at the end the total number of rare and frequent correctly read words is calculated. Only RWR (Rare Word Reading) score was used in this study. Cronbach's Alpha reliability coefficient for RWR is $\alpha=0.79$.

Short and long word reading. Average NLWE (Number of Letters in a Word where an Error is Made) is a ratio of the total number of letters in words and number of words where at least one error is made derived from seven reading materials: WNR subtest and two stories from TR subtest from RAT, three stories from DORF and a story from RC.

AR (Avoidance of Reading). AR was determined by asking five questions about a child's recent reading experience. The total score was derived by adding all obtained points and the result was a cumulative score. 
Cronbach's Alpha reliability coefficient for total score of AR is $\alpha=0.79$.

Intelligence. Eight subtests: Block Design, Similarities, Digit Span, Coding, Vocabulary, Letter-Number Sequencing, Matrix Reasoning, Symbol Search from WISC-IV ${ }^{\mathrm{LV}}$ (Wechsler, 2003; Latvian edition, 2013) were used to determine Full Scale IQ. Spearman-Brown reliability coefficient in a normative sample of Latvia for Full Scale IQ is $r_{s b}=0.94$ (Raščevska, Sebre, \& Ozola, 2013, p. 293).

\section{Procedure}

Data were collected individually with each child in three to four sessions at school. Tasks were given in the following sequence: questions about reading experience, RAT, WISC-IV ${ }^{\mathrm{LV}}$, separate reading and writing measures.

\section{Results}

Descriptive statistics ( $M, M d n, S D$, range of scores) of reading and writing variables (in raw scores) for control group and RD group are displayed in Table 1. Four of ten variables had a normal distribution for both groups together.

Table 1

Descriptive Statistics of Reading and Writing Variables for Control Group and Reading Disability Group in Raw Scores

\begin{tabular}{|c|c|c|c|c|c|c|c|c|}
\hline & \multicolumn{4}{|c|}{ Control group $(n=41)$} & \multicolumn{4}{|c|}{ RD group $(n=41)$} \\
\hline & $M$ & $M d n$ & $S D$ & Range & $M$ & $M d n$ & $S D$ & Range \\
\hline \multicolumn{9}{|c|}{ Reading variables } \\
\hline $\mathrm{LNF}^{*}$ & 79.56 & 81.00 & 14.01 & $55-109$ & 65.32 & 66.00 & 12.80 & $38-89$ \\
\hline $\mathrm{PSF}^{*}$ & 60.82 & 58.00 & 15.25 & $28-84$ & 53.05 & 55.00 & 18.12 & $20-83$ \\
\hline $\mathrm{NWF}^{*}$ & 39.27 & 40.00 & 9.01 & $18-58$ & 21.76 & 22.00 & 8.23 & $0-45$ \\
\hline DORF & 66.39 & 58.00 & 31.15 & $30-137$ & 32.05 & 30.00 & 14.11 & $3-68$ \\
\hline $\mathrm{RWR}^{*}$ & 17.07 & 18.00 & 3.66 & $8-23$ & 13.28 & 9.00 & 6.02 & $0-21$ \\
\hline $\mathrm{RC}$ & 10.05 & 10.00 & 3.58 & $0-15$ & 8.64 & 8.50 & 3.66 & $1-14$ \\
\hline $\mathrm{AR}$ & 2.18 & 2.00 & 1.80 & $0-5$ & 2.69 & 3.00 & 1.86 & $0-5$ \\
\hline NLWE & 7.40 & 7.30 & 0.76 & $6.00-9.67$ & 6.98 & 7.00 & 0.74 & $5.40-9.33$ \\
\hline \multicolumn{9}{|c|}{ Writing variables } \\
\hline NP & 9.27 & 8.00 & 4.99 & $0-18$ & 5.61 & 6.00 & 3.39 & $0-13$ \\
\hline ND & 3.95 & 2.00 & 3.95 & $0-19$ & 2.55 & 2.00 & 1.84 & $0-9$ \\
\hline
\end{tabular}

Notes. "Normal distribution according to Kolmogorov-Smirnov with Lilliefors Significance Correction for both groups together; LNF = Letter Naming Fluency; PSF = Phoneme Segmentation Fluency; NWF = Nonsense Word Fluency; DORF = DIBELS Oral Reading Fluency; RWR = Rare Word Reading; RC = Reading Comprehension; AR = Avoidance of Reading; NLWE = Average Number of Letters in a Word where an Error is Made; NP = Noun Spelling from a Picture; ND = Noun Spelling from a Dictation; $\mathrm{RD}=$ Reading Disability.

In order to find out the most predictive variables of $\mathrm{RD}$, controlling for the level of intelligence, transformation of raw scores of reading and writing variables into grade-corrected scores was computed. The transformation allowed for obtaining equivalent metrics for Full Scale IQ as a standardised score and other variables as raw scores, therefore, both variables could be included in a regression model. Raw scores were transformed into grade-corrected scores using the centring procedure (substituting the grade mean of general population for the score of each child). Descriptive statistics $(M, M d n, S D)$ of variables in grade-corrected scores, Pearson, or Spearman's rho correlations (for variables that did not have a normal distribution) between 
reading and writing variables and Full Scale IQ, and point biserial correlations with the group are displayed in Table 2.

In control group, Full Scale IQ had positive moderately strong significant correlations with five of ten variables: PSF, DORF, RC, NP and ND (see Table 2). In RD group, none of variables had a statistically significant association with Full Scale IQ.

Point biserial correlation indicated that all variables except AR had statistically significant correlations with the group (RD group corresponds to 1, control group to 0), thus, AR was not included in the regression model (see Table 2). The strongest negative statistically significant correlations were between NWF and the group and DORF and the group; the weakest negative significant correlations were between PSF and the group and ND and the group. Point biserial correlation between Full Scale IQ and the group was negative and moderately strong $\left(r_{p t b}=-0.40, p<0.01\right)$.

Table 2

Descriptive and Inferential Statistics of Reading and Writing Variables for Control Group and Reading Disability Group in Grade-Corrected Scores

\begin{tabular}{|c|c|c|c|c|c|c|c|}
\hline & \multicolumn{3}{|c|}{ Control group $(n=41)$} & \multicolumn{3}{|c|}{$\mathrm{RD}$ group $(n=41)$} & \multirow{2}{*}{$\begin{array}{l}r_{\mathrm{ptb}} \\
\text { with group }\end{array}$} \\
\hline & $M(M d n)$ & $S D$ & $r$ with FS-IQ & $M(M d n)$ & $S D$ & $r$ with FS-IQ & \\
\hline \multicolumn{8}{|c|}{ Reading variables } \\
\hline $\mathrm{LNFgc}^{\mathrm{a}}$ & $0(0.24)$ & 12.65 & 0.19 & $-14.24(-13.76)$ & 12.24 & 0.06 & $-0.50^{* *}$ \\
\hline $\mathrm{PSFgc}^{\mathrm{a}}$ & $0(0.67)$ & 14.88 & $0.35^{*}$ & $-7.59(-6.64)$ & 17.17 & -0.02 & $-0.23^{*}$ \\
\hline NWFgc & $0(1.95)$ & 7.87 & $0.14^{\mathrm{b}}$ & $-17.51(-17.70)$ & 8.14 & $-0.25^{b}$ & $-0.74^{* *}$ \\
\hline $\operatorname{DORFgc}^{\mathrm{a}}$ & $0(-3.29)$ & 21.08 & $0.36^{*}$ & $-34.34(-32.60)$ & 15.93 & 0.12 & $-0.68^{* *}$ \\
\hline RWRgc & $0(0.75)$ & 3.47 & 0.15 & $-7.58(-7.95)$ & 5.20 & 0.06 & $-0.66^{* *}$ \\
\hline $\mathrm{RCgc}^{\mathrm{a}}$ & $0(0.15)$ & 3.11 & $0.41^{* *}$ & $-1.65(-1.59)$ & 3.56 & 0.20 & $-0.24^{*}$ \\
\hline ARgc & $0(0)$ & 1.77 & $0.05^{\mathrm{b}}$ & $0.49(0.50)$ & 1.91 & $-0.13^{b}$ & 0.14 \\
\hline NLWEgc & $0(-0.11)$ & 0.73 & $-0.03^{b}$ & $-0.43(-0.45)$ & 0.79 & $0.07^{\mathrm{b}}$ & $-0.27^{*}$ \\
\hline \multicolumn{8}{|c|}{ Writing variables } \\
\hline NPge & $0(0.73)$ & 4.29 & $0.52^{* * \mathrm{~b}}$ & $-3.60(-3.80)$ & 2.87 & $0.25^{\mathrm{b}}$ & $-0.45^{* *}$ \\
\hline NDgc & $0(-1.50)$ & 3.92 & $0.54^{* * \mathrm{~b}}$ & $-1.39(-1.50)$ & 1.73 & $0.11^{\mathrm{b}}$ & $-0.23^{*}$ \\
\hline
\end{tabular}

Full Scale IQ had significant correlations with all variables except AR and NLWE (see Table 3). Significant correlations between variables varied from 0.24 to 0.71 . The strongest positive significant correlations were between NWF and DORF $(r=0.71, p<0.01)$ and between LNF and NWF $(r=0.68, p<$ $0.01)$. AR significantly correlated only with two of 10 variables: DORF $(r=-0.27, p<0.05)$ and LNF and NWF $(r=-0.24, p<0.05)$. Overall, the correlations between variables were acceptable for including all variables, except $\mathrm{AR}$, in the regression analysis.

In a binary logistic regression model (Forward: Conditional) with nine independent (IV) variables that significantly correlated with the dependent variable (DV) (see Table 2) and Full Scale IQ, four statistically significant variables were left $\left(\chi^{2}=72.67, d f=4, n=82, p<0.01\right)$ explaining $87 \%$ of variance (Nagelkerke $R^{2}$ ). Full Scale IQ was entered separately as the first variable, then the other nine variables were entered (Forward: Conditional). The model with Full Scale IQ alone as IV and group as DV was statistically significant $\left(\chi^{2}=\right.$ $11.71, d f=1, n=82, p<0.01$ ) and Full Scale IQ explained $22 \%$ of variance (Nagelkerke $R^{2}$ ). In the model with 
Full Scale IQ and other variables, in a second step Full Scale IQ and NWF accounted for 56\% (Cox \& Snell $R^{2}$ ) to $74 \%$ (Nagelkerke $R^{2}$ ) of the variance, the third step added DORF accounting for $61 \%$ to $82 \%$ of the variance, the fourth step added RWR accounting for $65 \%$ to $87 \%$ of the variance (see Table 4). Variables LNF, PSF, RC, AR, NLWE, NP, and ND were excluded from the regression model.

Table 3

Intercorrelations Among Reading and Writing Variables and Full Scale IQ $(N=82)$

\begin{tabular}{|c|c|c|c|c|c|c|c|c|c|c|}
\hline Variables & 1 & 2 & 3 & 4 & 5 & 6 & 7 & 8 & 9 & 10 \\
\hline \multicolumn{11}{|l|}{ 1. LNFgc } \\
\hline 2. PSFgc & $0.28^{*}$ & & & & & & & & & \\
\hline 3 NWFgc & $0.68^{* *}$ & $0.24^{*}$ & & & & & & & & \\
\hline 4. DORFgc & $0.47^{* *}$ & 0.18 & $0.71^{* *}$ & & & & & & & \\
\hline 5. RWRgc & $0.33^{* *}$ & $0.29^{* *}$ & $0.59^{* *}$ & $0.51^{* *}$ & & & & & & \\
\hline 6. $\mathrm{RCgc}$ & $0.28^{*}$ & $0.35^{* *}$ & $0.37^{* *}$ & $0.36^{* *}$ & 0.22 & & & & & \\
\hline 7. ARgc & $-0.24^{*}$ & -0.17 & -0.15 & $-0.27^{*}$ & -0.08 & 0.05 & & & & \\
\hline 8. NLWEgc & 0.11 & $0.35^{* *}$ & $0.28^{*}$ & 0.17 & $0.33^{* *}$ & $0.26^{*}$ & -0.11 & & & \\
\hline 9. NPgc & $0.44^{* *}$ & $0.25^{*}$ & $0.48^{* *}$ & $0.54^{* *}$ & $0.45^{* *}$ & $0.32^{* *}$ & -0.23 & $0.25^{*}$ & & \\
\hline 10. NDgc & 0.15 & $0.28^{*}$ & $0.27^{*}$ & $0.34^{* *}$ & $0.27^{*}$ & $0.44^{* *}$ & -0.01 & $0.31^{* *}$ & $0.26^{*}$ & \\
\hline 11. FS-IQ & $0.31^{* *}$ & $0.25^{*}$ & $0.31^{* *}$ & $0.43^{* *}$ & $0.33^{* *}$ & $0.40^{* *}$ & -0.10 & 0.09 & $0.51^{* *}$ & $0.41^{* *}$ \\
\hline
\end{tabular}

Notes. For variable full names see Table $1 ; \mathrm{gc}=$ grade-corrected; ${ }^{*} p<0.05 ;{ }^{* *} p<0.01 ; \mathrm{RD}=$ reading disability; FS-IQ $=$ Full Scale IQ.

Table 4

Binary Logistic Regression Analysis of Full Scale IQ, Reading and Writing Variables and Dependent Variable (Group) Using the Forward: Conditional Method $(N=82)$

\begin{tabular}{|c|c|c|c|c|c|}
\hline & $B$ & S.E. & $(\operatorname{Exp}) B$ & $R^{2}($ Cox \&Snell $)$ & $R^{2}$ (Nagelkerke) \\
\hline \multicolumn{6}{|l|}{ Step 1} \\
\hline FS-IQ & $-0.08^{* *}$ & 0.02 & 0.93 & \multirow[t]{2}{*}{0.17} & \multirow[t]{2}{*}{0.22} \\
\hline Constant & 7.22 & 2.25 & 1364.15 & & \\
\hline \multicolumn{6}{|l|}{ Step 2} \\
\hline FS-IQ & $-0.08^{*}$ & 0.04 & 0.92 & \multirow{3}{*}{0.56} & \multirow{3}{*}{0.74} \\
\hline NWFgc & $-0.24^{* *}$ & 0.05 & 0.79 & & \\
\hline Constant & 5.10 & 3.76 & 163.20 & & \\
\hline \multicolumn{6}{|l|}{ Step 3} \\
\hline FS-IQ & $-0.10^{*}$ & 0.05 & 0.91 & \multirow{4}{*}{0.61} & \multirow{4}{*}{0.82} \\
\hline NRFgc & $-0.22^{* *}$ & 0.07 & 0.80 & & \\
\hline DORFgc & $-0.09^{*}$ & 0.04 & 0.91 & & \\
\hline Constant & 4.69 & 4.13 & 108.70 & & \\
\hline \multicolumn{6}{|l|}{ Step 4} \\
\hline FS-IQ & $-0.13^{*}$ & 0.06 & 0.87 & \multirow{5}{*}{0.65} & \multirow{5}{*}{0.87} \\
\hline NRFgc & $-0.21^{* *}$ & 0.08 & 0.81 & & \\
\hline DORFgc & $-0.13^{*}$ & 0.05 & 0.88 & & \\
\hline RWRgc & $-0.37^{*}$ & 0.17 & 0.69 & & \\
\hline Constant & 5.67 & 4.83 & 290.44 & & \\
\hline
\end{tabular}

\section{Discussion and Conclusion}

The aim of this study was to find the most predictive reading and writing skills for RD in Latvian 
orthography, controlling for the level of intelligence. The findings of this study showed that RD in Latvian orthography was significantly predicted by nonsense word fluency, oral reading fluency and accuracy of rare word decoding, if the level of intelligence was controlled. Nonsense word fluency explained the most variance of RD in Latvian language, and is considered to be one of the important predictors of RD in regular and irregular orthographies (Herrmann, Matyas, \& Pratt, 2006; Velluntino et al., 2004). Nonsense word reading requires phonological processing - decoding based on direct grapheme-phoneme correspondence. Even though Latvian language has a regular orthography and graphemes-phonemes correspondences are simple, phonological processing is the most delayed in Latvian primary children with RD. Phonological processing develops from phonological ability. Studies have indicated that phonological ability is one of the most powerful predictors of RD in various orthographies (Landerl et al., 2013; Lopez-Escribano \& Katzir, 2008). However, in the present study, phonological ability reflected by phoneme segmentation fluency did not predict RD. If the children with RD had decreased phonological ability in pre-reading stage, they might have developed sufficient phonological ability in Grades 1 and 2 through phonemic instruction (Furnes \& Samuelsson, 2010), but they still have not sufficiently automatised the next, more complex skill: decoding based on direct letter-sound correspondence.

Oral reading fluency was the second strongest predictor of RD in our model, and this finding was supported by studies in German language that showed fluency of a connected text as one of the important indicators of RD (Wimmer, Mayringer, \& Landerl, 1998). In comparison to nonsense word reading, reading of a connected text involves both phonological processing and sight word reading, moreover, the context gives assistance for anticipation of the next words while reading.

The third significant predictor of RD in Latvian children was accuracy or rare word decoding. In some way, the words which are met rarely in the experience of the children can be considered similar to nonsense words because it is more difficult or even impossible to retrieve the word from lexical storage. However, less frequent words have typical structure of words from a particular language, but nonsense words do not. The results in some ways were in contradiction with previous findings in German, but were supported by a study in Spanish. German children with RD could read less frequent words as accurately as children with normal reading ability, but they read those words much slower (Frith et al., 1998), however, Spanish children with RD were less accurate in low frequency word reading than children from normative sample (Lopez \& Jimenez-Gonzalez, 1999).

There were some other reading and writing skills that were not found to be important predictors of RD as the skills mentioned above. For example, accuracy of long word reading did not differentiate RD from the control group, even though word length was considered to be an important predictor of RD (Davies, Cuetos, \& Glez-Seijas, 2007). In the present study, long word reading accuracy was measured by average word length where an error is made, and children from both groups on average made errors in words of seven letters, thus, the accuracy of long word reading was not delayed in children with RD while reading in regular Latvian orthography. Reading comprehension also did not play an important role in the prediction model of RD and had quite a weak ability to differentiate children with and without $\mathrm{RD}$, although, a previous study with Latvian primary pupils from the general population advocated for the association between word reading fluency and reading comprehension (Briede, 2005). The avoidance of reading could not differentiate children with and without RD and was not included in the model. Avoidance of reading very often is a consequence of reading failure in children with RD (Paris et al., 1999) and, moreover, AR can result in decreased reading mastery in the 
future (Baker \& Wigfield, 1999). The results of the current study revealed that avoidance of reading to some degree was prevalent in children with and without RD. Perhaps, further avoidance of reading should be investigated in a more extensive way by also including observations and parent or teacher reports.

One of the important facets of the present study was controlling for intelligence. The results showed that IQ explained some variance and was an important predictor of RD. The analysis of associations between IQ and reading and writing skills separately in each group advocates that Latvian primary pupils from the general population with higher IQ have higher phoneme segmentation fluency and oral reading fluency, better reading comprehension and better writing skills. However, IQ of Latvian primary pupils with RD was not associated with any measured reading and writing skills. No association between IQ and RD has been proposed for identifying this disorder (World Health Organization, 1992). However, our results pointed to the importance of controlling for IQ in research to obtain more accurate results.

There were a few limitations of this study. The first limitation refers to the formation of the RD group. Due to the fact that the identification approaches of RD and other developmental disorders in Latvia are still in development and there are very few children diagnosed with RD in primary school, in the present study the group of RD was based on teacher observations of persistent reading difficulties and a measure of reading achievement as an affirmative criterion. Teachers in their observations might be subjective, leaving the possibility that some children with RD were not identified, but some of the nominated children with reading difficulties that did pass the criterion might be having some other primary disorders, such as attention deficit, about which no specific information was available. The group of RD comprised only children from comprehensive schools, but in Latvia there are also special schools where a number of children with RD might be studying.

The second important limitation was related to the measure of Reading Achievement Test (Raščevska, Paegle, \& Mencis, 2013) as a criterion for RD. The typical measures of reading achievement include decoding and reading comprehension. In the current study, only decoding was used as a criterion because most of the primary pupils from the RD group did not reach the reading fluency frontier to be assessed on RC. Even though there was a strong association between decoding and reading comprehension in developing readers, the construct of reading was represented only partly and the children with reading comprehension disability were missing in the RD group.

The third limitation of this study was related to SES (the social economic status) for both groups. The information about SES was not obtained in this study, and there was a small chance that the children with RD were coming from families with lower SES compared to control children. However, according to the present economic situation in Latvia, there are no significant material differences between inhabitants of the country, with the majority of the population belonging to the middle class and only a small percent having very low or high income. Moreover, the matched control child for each child with RD came from the same school and very often from the same grade, and the SES differences should not be present.

In summary, the findings of this study showed that the most important predictors of reading and writing skills for RD in a regular orthography were nonsense word reading, oral reading fluency, and accuracy of rare word reading, when the level of intelligence was controlled. Intelligence itself explained a portion of variance in $\mathrm{RD}$, thus, intelligence is an important predictor of $\mathrm{RD}$ and should be included in further research models of $\mathrm{RD}$. 


\section{References}

American Psychiatric Association. (2013). Diagnostic and statistical manual of mental disorders (5th ed.). Arlington, V.A.: American Psychiatric Publishing.

Aro, M. (2006). Learning to read: The effect of orthography (Unpublished doctoral dissertation, University of Jyvaskyla, Finland).

Baker, L., \& Wigfield, A. (1999). Dimensions of children's motivation for reading and their relations to reading activity and reading achievement. Reading Research Quarterly, 34, 452-477.

Briede, A. (2005). Kognitīvo un lingvistisko faktoru ietekme uz pirmās klases skolēnu lasīšanas sapratni (The impact of cognitive and liguistic factors on reading comprehension of students from Grade 1) (Unpublished master's thesis, University of Latvia, Latvia).

Catts, H., \& Kamhi, A. (2005) (Eds.). The connections between language and reading disabilities. Mahwah, N.J.: Erlbaum.

Davies, R., Cuetos, F., \& Glez-Seijas, R. M. (2007). Reading development and dyslexia in a transparent orthography: A survey of Spanish children. Annals of Dyslexia, 57, 179-198. doi:10.1007/s11881-007-0010-1

Frith, U., Wimmer, H., \& Landerl, K. (1998). Differences in phonological recoding in German and English speaking children. Scientific Studies of Reading, 2, 31-54.

Furnes, B., \& Samuelsson, S. (2010). Predicting reading and spelling difficulties in transparent and opaque orthographies: A comparison between Scandinavian and US/Australian children. Dyslexia, 16, 119-142.

Good, R. H., Kaminski, R. A., Cummings, K., Dufour-Martel, Ch., Petersen, K., Powell-Smith, K., Stollar, S., \& Wallin, J. (2011). Dynamic indicators of basic early literacy skills: DIBELS next assessment manual. Location: Dynamic Measurement Group.

Herrmann, J. A., Matyas, T., \& Pratt, Ch. (2006). Meta-analysis of the nonword reading deficit in specific reading disorder. Dyslexia, 12, 195-221. doi: 10.1002/dys.324

Kortteinen, H., Närhi, V., \& Ahonen, T. (2009). Does IQ matter in adolescents' reading disability? Learning and Individual Differences, 19, 257-261.

Landerl, K., Ramus, F., Moll, K., Lyytinen, H., Leppänen, P. T., Lohvansuu, K.,... Longeras, E. (2013). Predictors of developmental dyslexia in European orthographies with varying complexity. Journal of Child Psychology \& Psychiatry, 54(6), 686-694. doi:10.1111/jcpp.12029

Landerl, K., Wimmer, H., \& Frith, U. (1997). The impact of orthographic consistency on dyslexia: A German-English comparison. Cognition, 63, 315-334.

Lopez, M. R., \& Jimenez-Gonzalez, J. E. (1999). An analysis of the word naming errors of normal readers and reading disabled children in Spanish. Journal of Research in Reading, 22(2), 180-197.

Lopez-Escribano, K., \& Katzir, T. (2008). Are phonological processes separate from the processes underlying naming speed in a shallow orthography? Electronic Journal of Research in Educational Psychology, 6(3), 641-666.

Orlovska, M., \& Rascevska, M. (2014a). Development and psychomentric properties of Latvian Frequent and Rare Word Reading Test (Unpublished manuscript, University of Latvia, Latvia)

Orlovska, M., \& Rascevska, M. (2014b). Development and psychomentric properties of Latvian reading comprehension task (Unpublished manuscript, University of Latvia, Latvia)

Paris, S. G., Wasik, B. A., \& Turner, J. C. (1991). The development of strategic readers. In R. Barr, M. L. Kamil, P. Mosenthal, \& P. D. Pearson (Eds)., Handbook of reading research (Vol. 2, pp. 609-640). White Plains, N.Y.: Longman.

Raščevska, M., Orlovska, M., Griškeviča, I., Vabale, A., Ozola, E., \& Legzdin̄š, P. (2013a). Agrīnāslasītprasmesattīstībasrādītāju DIBELS Next latviešuvalodasversija (Latvian edition of Dynamic Indicators of Basic Early Literacy Skills). Rīga: McĀbols.

Raščevska, M., Paegle, Dz., \& Mencis, J. Jr. (2013). Latviešuvalodassasniegumutestuvadīšanasrokasgrāmata (Assessment manual of Latvian Language Achievement Tests). Rīga: LU Akadēmiskaisapgāds.

Raščevska, M., Vabale, A., Griškeviča, I., Orlovska, M., Ozola, E., Koḷesovs, A.,... Mutule, S. (2013b). Agrīnāslasītprasmesattīstībasrādītāju DIBELS Next interpretācijasrokasgrāmata (Interpretation manual of Dynamic Indicators of Basic Early Literacy Skills). Rīga: McĀbols.

Raščevska, M., Sebre, S., \& Ozola, E. (2013). Veksleraintelektatestabērniem-ceturtaisizdevumslatviešuvalodā (Wechsler Intelligence Scale for Children-Fourth LV Edition). Location: NCS Pearson.

Siegel, L. S. (1988). Evidence that IQ scores are irrelevant to the definition and analysis of reading disability. Canadian Journal of Psychology, 42, 201-215.

Skadina, I., Rehm, G., \& Uszkoreit, H. (Eds.) (2012). The Latvian language in the digital age. Berlin: Springer. 
Sprugevica, I., \& Høien, T. (2004). Relations between enabling skills and reading comprehension: A follow-up study of Latvian students from first to second grade. Scandinavian Journal of Psychology, 45, 115-122.

Stanovich, K. E. (1986). Matthew effects in reading: Some consequences of individual differences in the acquisition of literacy. Reading Research Quarterly, 21, 360-407.

Vellutino, F. R., Fletcher, J. M., Snowling, M. J., \& Scanlon, D. M. (2004). Specific reading disability: What have we learned in the past four decades? Journal of Child Psychology and Psychiatry, 45(1), 2-40.

Wechsler, D. (2003). Wechsler intelligence scale for children-fourth edition. San Antonio, T.X.: Psychological Corporation.

Wigfield, A., \& Guthrie, J. T. (1997). Relations of children's motivation for reading to the amount and breadth of their reading. Journal of Educational Psychology, 89, 420-432.

Wimmer, H., Mayringer, H., \& Landerl, K. (1998). Poor reading: A deficit in skill-automatization or a phonological deficit? Scientific Studies of Reading, 2, 321-340.

World Health Organization. (1992). ICD-10 classifications of mental and behavioural disorder: Clinical descriptions and diagnostic guidelines. Geneva: World Health Organisation.

Ziegler, J. C., Perry, C., Ma-Wyatt, A., Ladner, D., \& Schulte-Korne, G. (2003). Developmental dyslexia in different languages: Language-specific or universal? Journal of Experimental Child Psychology, 86, 169-193. 